\title{
Using spindle noise to monitor tool wear in a turning process
}

\author{
N. Seemuang ${ }^{1} \cdot$ T. McLeay ${ }^{2} \cdot$ T. Slatter $^{1}$ (D)
}

Received: 8 July 2015 / Accepted: 21 December 2015 /Published online: 29 January 2016

(C) The Author(s) 2016. This article is published with open access at Springerlink.com

\begin{abstract}
A tool condition monitoring system can increase the competitiveness of a machining process by increasing the utilised tool life and decreasing instances of part damage from excessive tool wear or tool breakage. This article describes an inexpensive and non-intrusive method of inferring tool condition by measuring the audible sound emitted during machining. The audio signature recorded can be used to develop an effective in-process tool wear monitoring system where digital filters retain the signal associated with the cutting process but remove audio characteristics associated with the operation of the machine spindle. This study used a microphone to record the machining sound of EN24 steel being face turned by a CNC lathe in a wet cutting condition using constant surface speed control. The audio signal is compared to the flank wear development on the cutting inserts for several different surface speed and cutting feed combinations. The results show that there is no relationship between the frequency of spindle noise and tool wear, but varying cutting speed and feed rate have an influence on the magnitude of spindle noise and this could be used to indicate the tool wear state during the process.
\end{abstract}

\section{T. Slatter}

tom.slatter@sheffield.ac.uk

N. Seemuang

nseemuang1@sheffield.ac.uk

T. McLeay

t.mcleay@sheffield.ac.uk

1 Department of Mechanical Engineering, University of Sheffield, Sheffield, UK S1 3JD

2 Advanced Manufacturing Research Centre, University of Sheffield, Rotherham, UK S60 5TZ
Keywords Tool condition monitoring · Turning · Tool wear

\section{Introduction}

The automation of manual tasks is an important part of competitive and capable manufacturing processes. It is important to prevent productivity losses due to excessive tool changes or quality losses due to excessive tool wear or breakage [1]. In terms of tool wear, not only can such a tool failure be avoided but also maximum use should be obtained from the tool. Recent developments in cutting tool materials and optimisation of machining process parameters have allowed longer tool life, but the tools still wear out when used over extended periods of time. Worn tools have a direct effect on the surface finish and geometrical accuracy of the finished workpiece [2]. Unplanned tool replacement can cause machine downtime and part non-conformance leading to economic loss [3]. To avoid this, tool condition monitoring systems have been developed which can warn the operator of the condition of the tool.

Tool wear monitoring systems have been developed over a long period of time and numerous methods have been proposed such as those summarised by Siddhpura et al., Teti et al., and Rehorn et al. [1, 3, 4]. An all-encompassing system has yet to be developed but success has been found with some research efforts. Methods can be categorised into direct (radioactive, optical, electrical resistance, etc.) and indirect methods (acoustic emission, spindle motor current, cutting force, vibration, temperature, sound, etc.) [5].

Currently, the use of multi-sensory signals, such as acoustic emission, cutting force, vibration, current or power consumption of spindle motor, has been adopted and all sensory data is fused using artificial intelligence (AI) such as neural network and fuzzy logic to increase the reliability and robustness of the 
system. Several AI algorithms and signal processing techniques have been used to develop the tool wear monitoring system summarised by Teti et al. [4] and Worden et al.[6]. Abellan-Nebot et al. [7] suggested the six key issues for the development of intelligent machining systems: sensor selection, signal processing techniques, sensorial features normally used, feature extraction and selection, design of experiment (DoE) and characteristics of AI techniques. Several systems based on AI approach have been successfully developed in the past as reported in this article. However, the majority of tool monitoring research has applied expensive sensing systems not suitable for production, such as force dynamometers. Even with expensive data acquisition hardware, obtaining highquality data to train the system is difficult and timeconsuming because of the complexity of the signals that can be recorded from an operating machine. Ultimately, the reduction of the cost, intrusive nature and number of sensors will promote industry application of these systems.

In this present work, audio signature in t process was reviewed to extract features which are sensitive to tool wear. Much of the vibrations being excited in the cutting zone during machining are in the range at which they can be heard by the operator, and therefore be recorded by a standard audio microphone. Machine operators have been effective in the detection of unacceptable cutting conditions, inferred through the audible emissions from the cutting process. Microphones, being a non-contact sensor, are very easy and flexible to instal in the machine and there are a wide variety of inexpensive models with different performance characteristics. Microphones have been used extensively for chatter detection and have also been used on occasion to monitor tool wear in turning processes [8-10].

In previous studies, Teti et al. [4] reviewed several sound measurement techniques used to monitor flank wear during the turning process. Several studies confirm that tool wear state is correlated to the sound emitted during the machining found in the following reviews.

Sound signature in the turning process was studied in order to find the relationship between sound signal and cutting speeds and feed rates. Sound pressure in a time domain has been used by several studies to observe the change in amplitude according to tool wear $[8,9,11,12]$.

Tekiner used a microphone connected to a computer to record the cutting sounds in order to determine the best cutting parameters for cutting AISI 304 stainless steel according to process sound [11]. It was observed by Raja that the change of cutting parameters, cutting sound pressure levels also change and an increase in tool wear resulted in an increase of sound signal amplitude [8]. Similarly, Kopac et al. concluded that progressive tool wear correlates with an increase in amplitude of the recorded sound between 6 and $20 \mathrm{kHz}$ which is above the frequency range within which machine background noise is normally found [9]. Audio techniques were also used by Quintana to determine the stability lobe diagram (SLD) in a milling process by applying 3D sound mapping methodology. A microphone was mounted inside the milling machine, and audio signals from 600 cutting conditions were recorded and processed. The sound pressure level of each condition was plotted on a grid to identify the stable and unstable cutting conditions that are a key to avoiding chatter in the milling process [12].

The analysis of fast fourier transforms (FFT) of audible sound generated from the turning process was used by $\mathrm{Lu}$ et al. to introduce the model for tool wear monitoring [13]. This model includes the main effects of tool wear on system dynamics during stable cutting of lathe machine. Alonso et al. proposed a sound-processing technique using singular spectrum analysis (SSA). This processing technique was used to extract the sound features from the cutting zone during the turning process. The results showed that the extracted features from sound and feed motor current signals correlate with tool wear state [14]. Raja used sound signal analysis, using the Hilbert-Huang Transform (HHT), to monitor flank wear [8, 15]. Cutting sounds from three states of tool wear (fresh, slightly worn, and severely worn) were recorded under several cutting conditions, and it is claimed that this signal processing method can be considered as simple and reliable for flank wear monitoring.

As flank wear has a direct effect on the surface finish of a machined workpiece, measuring roughness of machined surfaces is normally performed to monitor the flank wear development. Surface roughness by machine vision techniques and sound processing techniques were attempted to develop the tool condition monitoring systems, which can be found in a number of studies. Manan et al. investigated the correlation between tool wear and machined surface and sound pattern from turning process. Sensorial features from a sound signal were extracted for classifying tool wear states. The results found that the propose system developed by machine vision and sound processing techniques can be utilised to effectively monitor the condition of the cutting tool [10]. Similarly, flank wear, the surface roughness of machined sample, and machine

Table 1 Typical composition (wt\%) of EN24 steel

\begin{tabular}{lllllllll}
\hline $\mathrm{C}$ & $\mathrm{Si}$ & $\mathrm{Mn}$ & $\mathrm{S}$ & $\mathrm{P}$ & $\mathrm{Cr}$ & $\mathrm{Mo}$ & $\mathrm{Ni}$ & $\mathrm{Fe}$ \\
\hline $0.36 / 0.44$ & $0.10 / 0.35$ & $0.45 / 0.70$ & $0.040 \mathrm{Max}$ & $0.035 \mathrm{Max}$ & $1.00 / 1.40$ & $0.20 / 0.35$ & $1.30 / 1.70$ & Bal. \\
\hline
\end{tabular}


Table 2 Process parameters used during machining trials

\begin{tabular}{llll}
\hline Condition & $\begin{array}{l}\text { Cutting speed } \\
(\mathrm{Vc})(\mathrm{m} / \mathrm{min})\end{array}$ & $\begin{array}{l}\text { Feed rate }(F) \\
(\mathrm{mm} / \mathrm{rev})\end{array}$ & $\begin{array}{l}\text { Depth of cut } \\
(D)(\mathrm{mm})\end{array}$ \\
\hline 1 & 300 & 0.30 & 0.5 \\
2 & 300 & 0.35 & 0.5 \\
3 & 300 & 0.40 & 0.5 \\
4 & 280 & 0.35 & 0.5 \\
5 & 280 & 0.40 & 0.5 \\
6 & 320 & 0.35 & 0.5 \\
7 & 320 & 0.40 & 0.5 \\
\hline
\end{tabular}

tool power consumption were used by Tekiner et al. as a criteria to determine the best cutting condition for the machining of AISI 304 stainless steel [11]. Downey used a microphone, connected to a laptop via a sound card, in order to record the cutting sound in the turning machine. The cumulative magnitude of sound spectrum and surface roughness ( $\mathrm{Ra}$ ) was compared for the full life of cutting tool. The variation of sound spectrum can be compared to the state of the cutting tool interface. It can also notice the change in audible sound spectra between normal tool and end of tool life [16].

To enhance reliability, multi-sensorial features from several sensors can be combined in order to develop a tool wear prediction and classification model by using artificial intelligence; this is known as sensor fusion. Alonso et al. used sound and feed motor current to develop the monitoring system to detect the tool wear. The features extracted from sound and feed motor current signals by SSA correlate with tool wear state and were trained by neural network to estimate the tool flank wear [14]. A radial basis function was used by Manan to train the network which consists of features extracted from sound signal and surface roughness [10]. This classification model is able to recognise tool wear states which classify tool states (defined as 'sharp', 'semi-dull' and 'dull'), and the proposed system can be utilised to effectively monitor the condition of the cutting tool. Tangjitsitcharoen et al. used a sensor fusion-based approach to monitor tool wear using sound, force, vibration and AE signals and found that the energy spectrum density of sound and AE signals are sensible to tool wear [17].

Nevertheless, the major limitation of using a microphone to record the cutting sound is the background noise from the environment. This can be from vibrations in the cutting zone, vibrations caused by the machine tool drive system, external sources and, in particular, noise from the flowing coolant.

This article describes an inexpensive method of obtaining tool condition information from an operating machine tool by recording the sound emitted during machining and filtering the unwanted noise to improve the effectiveness of an inprocess tool wear monitoring system. The data obtained can also be used as a basic tool condition monitoring system in its own right.
It should be noted that throughout this article, unless specifically referred to as 'signal noise' (as in 'signal to noise ratio'), all references to 'noise' should be taken to mean the sound (noise) that is emitted from the cutting zone or from the machine itself.

\section{Experimental setup and procedure}

\subsection{Equipment and cutting conditions}

A CNC lathe (MORI SEIKI NT4300DCG) was used to machine EN24 steel (Table 1). The workpiece was a round bar with a diameter of $200 \mathrm{~mm}$ and of a length always shorter than its diameter. It was cantilevered in the machine using a threejaw chuck with a face turning process performed across its free end. All trials were conducted using CVD-coated carbide tooling inserts of a grade commonly used for the basic turning of EN24 and meeting ISO DNMG 1506 08-PM (ANSI DNMG 442-PM). In production, an operator would typically use the process parameters for cutting as suggested by the tooling manufacturer for the workpiece in question. In this work, in order to accelerate tool wear and to consume less workpiece material, process parameters were deliberately chosen to be in excess of those typically used for these inserts. Similarly, in order to reduce the number of machining trials conducted, only two of the three main process variables, feed and cutting speed, were varied (Table 2), with depth of cut being constantly set at $0.5 \mathrm{~mm}$. The cutting zone was flood cooled with Hocut795b throughout all the experimental trials.

The experimental setup is shown in Fig. 1. A PCB Piezotronics 130E21 microphone (Fig. 1a) was used to record the cutting sound during the machining process. These types of microphones are of a free-field condenser

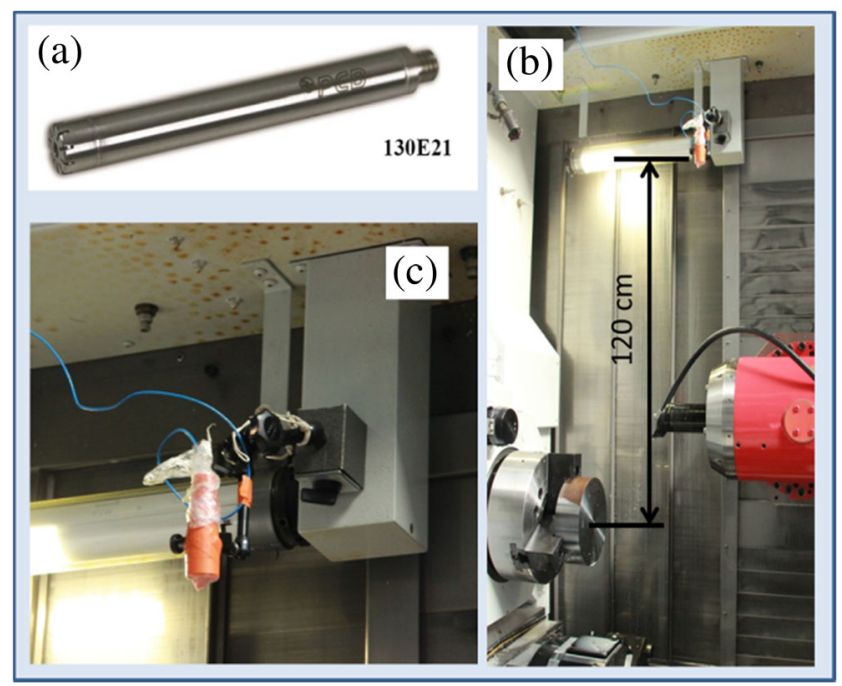

Fig. 1 Arrangement of experimental apparatus showing the microphone (a) and its position in the machine tool (b, c) 


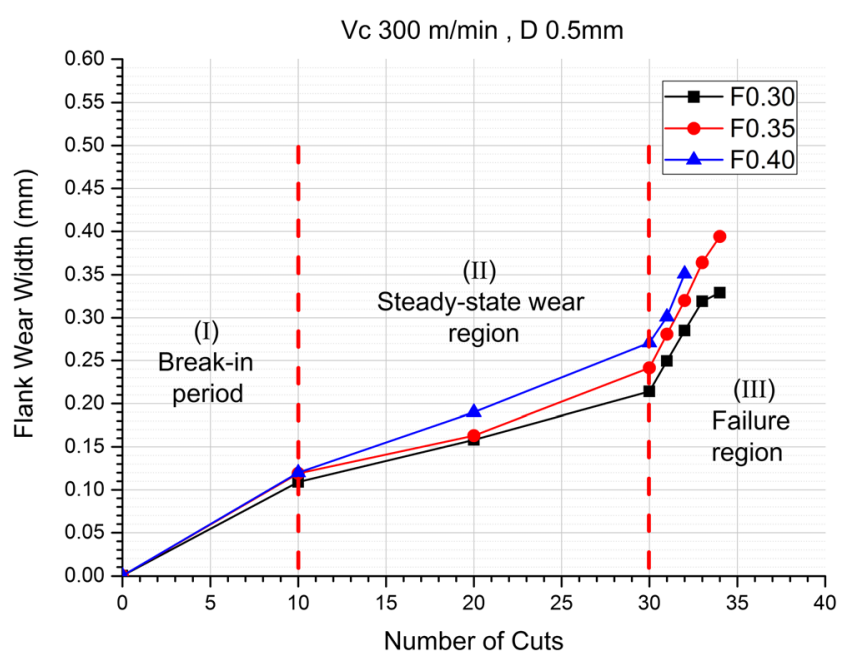

Fig. 2 Typical tool wear evolution dataset for cutting conditions 1-3 classified into three wear states

type and have a frequency response of $20-10,000 \mathrm{~Hz}$ with a dynamic range $>122 \mathrm{~dB}$. They also are prepolarised and have an integral preamplifer which reduces the complexity and cost of installation.

Prior to the experimental trials, the machine was observed conducting a typical flood-cooled turning operation to assess the optimum position for the microphone. It was discovered that a position $1.2 \mathrm{~m}$ away from the cutting zone was the best compromise between achieving a high quality recording, minimising potential damage from coolant spray and providing a secure location to attach a magnetic stand to the machine (Fig. 1b). The microphone was also suitably enclosed to further minimise the chance of damage from the coolant. (Fig. 1c). The location of the microphone inside a machine also isolates it from any significant noise from nearby machines.

The microphone was connected to a National Instruments NI-9234 DAQ. The sound was sampled at $50 \mathrm{kS} / \mathrm{s}$; analysis was performed using National Instruments LabView and The Mathworks Matlab software. All sound signals recorded from the microphone were transformed into the frequency domain by FFT.

\subsection{Experimental methodology}

All trials were conducted until the observable flank wear width (FWW) on the main cutting edge exceeded $0.4 \mathrm{~mm}$. For each condition, the inserts were removed from the tool holder and the flank wear width was measured optically (to ISO-3685) every 10,20 and 30 cuts. The frequency of measurement was then increased as the wear limit was approached. The tool wear measurements and the audio signature for each test were then compared in order to establish the relationship between tool wear and sound signal. Figure 2 illustrates the observed relationship between the width of flank wear width and the number of cuts for three typical data sets obtained in the experiment. In this particular example, the three datasets represent the measured flank wear width produced by three feed rates, $0.30,0.35$ and $0.40 \mathrm{~mm} / \mathrm{rev}$, at constant cutting speed
Fig. 3 Flank wear development from cutting condition $\mathrm{Vc}=300 \mathrm{~m} / \mathrm{min}$ and $F=0.35 \mathrm{~mm} / \mathrm{rev}$ (a) $10^{\text {th }} \mathrm{cut}$

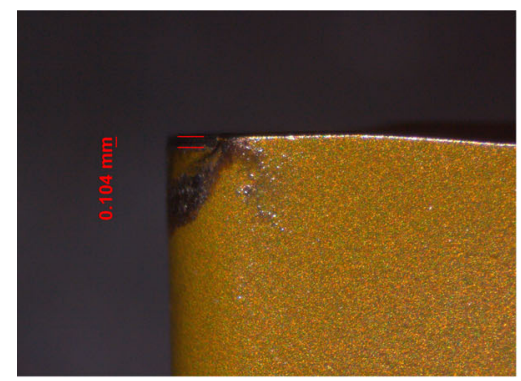

(c) $30^{\text {th }}$ cut

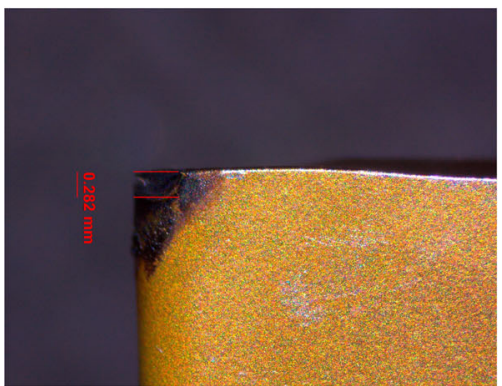

(b) $20^{\text {th }}$ cut

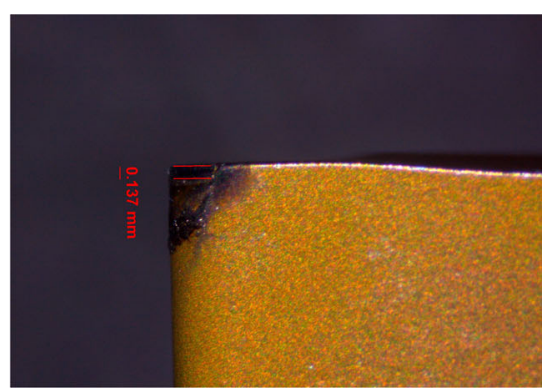

(d) $34^{\text {th }}$ cut

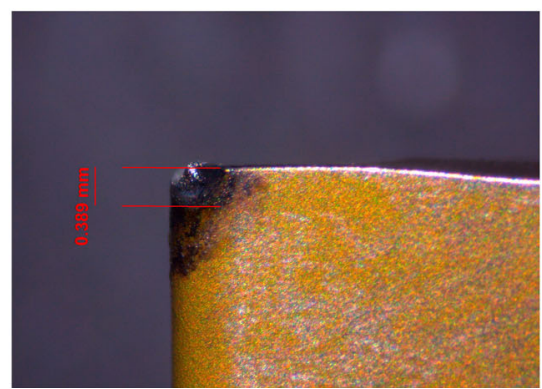




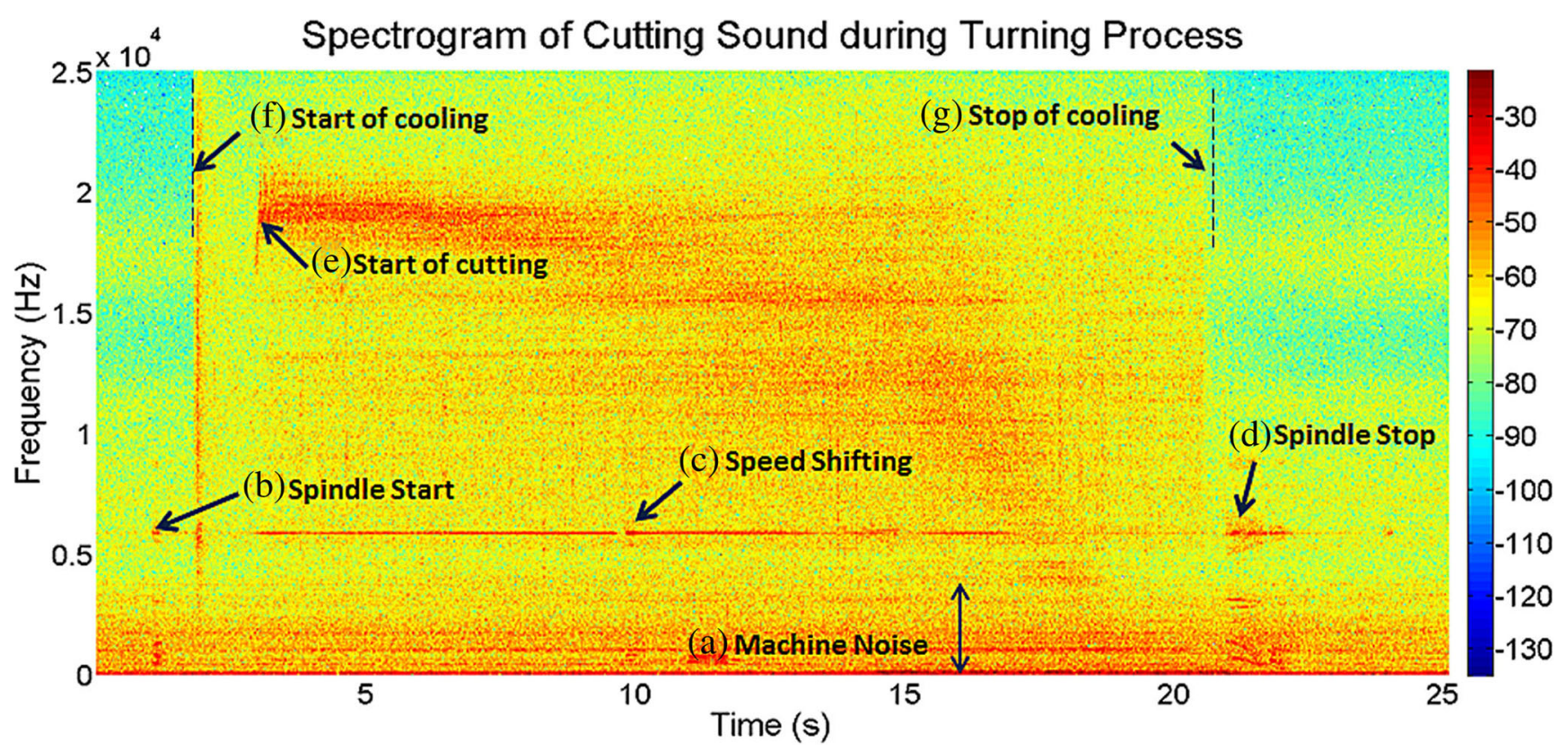

Fig. 4 Spectrogram of audio recorded from cutting cycle

$300 \mathrm{~m} / \mathrm{min}$ (cutting conditions $1-3$ in Table 2). Each data point represents a single measurement. It is seen that the tool wear state is classified into three regions; breaking-in period, steady-state wear region and failure region as shown by red dash lines. Figure 3 shows flank wear width developed on the cutting insert, which was used in cutting condition 2 .

\section{Results and discussion}

\subsection{Observation of the sound from a cutting cycle}

The multiple sources of sound in the cutting process include those from the cutting mechanism itself, sound from the machine tool spindle, drives and coolant delivery and sound from adjacent machines and workshop activities in a production environment. Previous studies have shown correlation between sound emitted from the cutting mechanism and the flank wear of the cutting insert and that the amplitude of sound signal increases with increasing tool flank wear when cutting low carbon and mild steels $[8,9$, 15]. It has also been reported that the machine and workshop sound is an unwanted disturbance with respect to the tool monitoring task [9].

In this work, the audio recorded from each test was analysed in the time-frequency domain by short-time Fourier transform (STFT) in order to establish the frequency content in the audio signature that could be then used for tool condition monitoring. The analysis produced a spectrogram that represents the sound signal resulting from the machining process. The example spectrogram shown in Fig. 4 displays the
Fig. 5 Power spectrum of (a) machine background noise with no tool engagement (b) during cutting operation

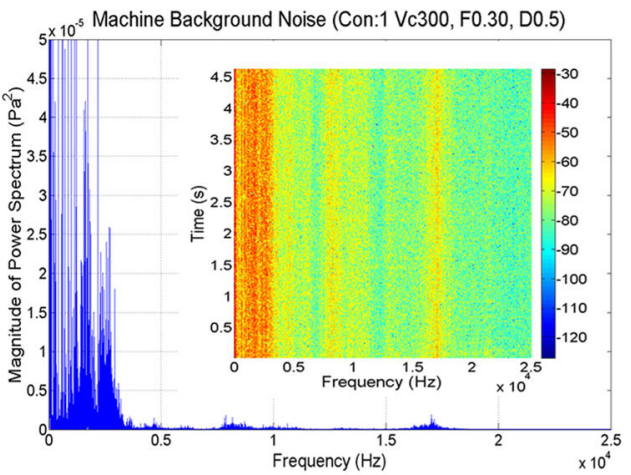

(a)

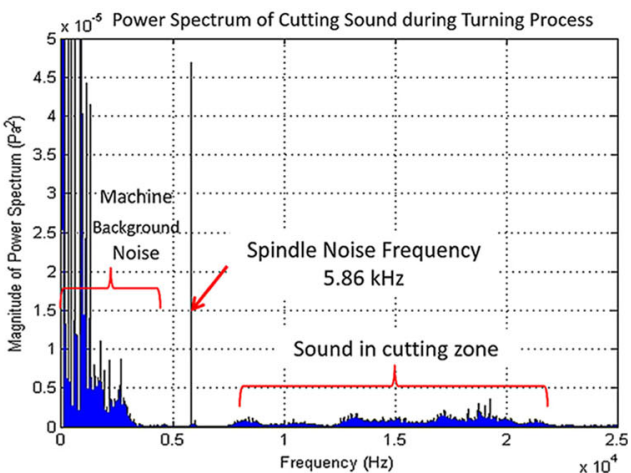

(b) 
magnitude of frequency spectrum of the cutting sound recorded by the microphone during a 25 -s cutting cycle at cutting condition 1 . The horizontal axis represents time, whilst vertical axis displays frequency. The amplitude of a particular frequency is represented by the colour intensity of each point.

The various events that occurred during the turning process are labelled. Each of these is clearly heard by the human ear when observing the machining process. It is seen that throughout the cycle, the sound signal was contaminated by machine background noise (A) which has a frequency of $0-3 \mathrm{kHz}$. The machine spindle is shown running by the higher amplitude horinzontal line between points (B and $\mathrm{D}$ ) with an example of spindle speed shifting at point $(\mathrm{C})$. The increase in noise amplitude representing the engagement of the cutting tool with the workpiece is shown at point (E). All trials were conducted in a wet condition so a broadband frequency of coolant being applied to the cutting zone is also depicted ( $F$ to $\mathrm{G}$ ). To isolate the machine background noise, a recording of the machine running with no cutting occurring was made and Fig. 5a shows the test result in the frequency domain by the power spectrum of the sound signal.

Clearly, the background noise frequency in Fig. $5 \mathrm{a}$ and b is in the range of $0-3 \mathrm{kHz}$, and several studies agree that background machine noise can be identified in the range of $0-2 \mathrm{kHz}$ [9]. It should be noted that although the machine used in these experiments has not been studied to fully characterise the stability of its noise output, the data presented in Fig. 5 can be considered typical across all the experiments conducted for this work. This means that this part of the signal can be easily filtered without any effect to the signal of interest. It should be noted, that whilst chatter detection systems should include this frequency content, the tool condition monitoring objective in this case study,

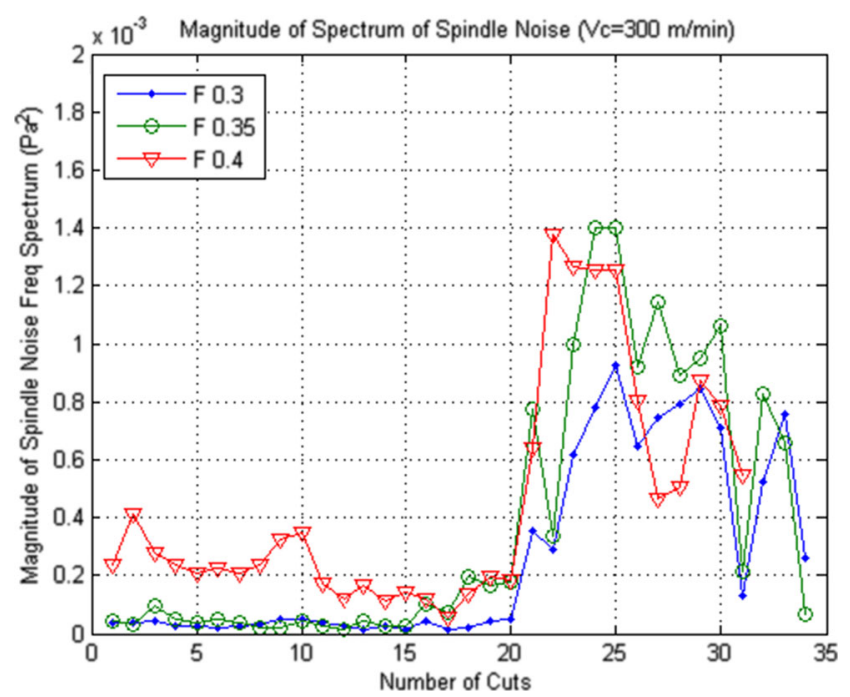

Fig. 6 Peak spindle-sound frequency magnitude vs the number of cuts for a varying feed rate and constant cutting speed

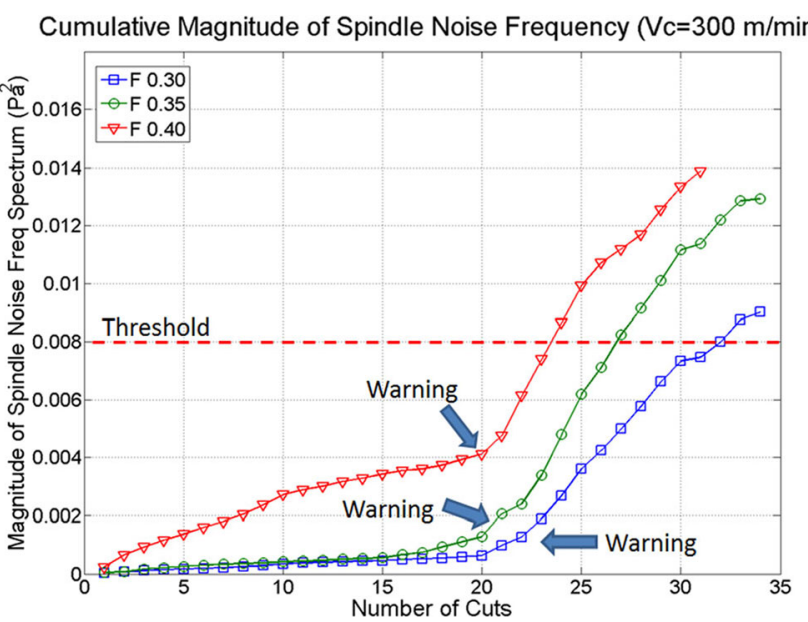

Fig. 7 Cumulative magnitude for a varying feed rate and constant cutting speed

under non-chatter conditions, may benefit from removing this data.

Similarly, further observation of Fig. 4 identify the noise from spindle motor and can be seen as a long horizontal high-intensity line from point (B) to (D). This noise of spindle motor is found at $5.86 \mathrm{kHz}$ as shown by power spectrum in Fig. 5b. This peak spindle-sound frequency magnitude is defined as a promising feature of tool condition monitoring.

Point (B) depicts the spindle start time as the motor is speeding up to the desired rotational speed. Note the spindle is accelerating due to the facing operation requiring constant surface speed. The maximum RPM of the spindle is reached in the middle of cutting time (point $\mathrm{C}$ ), where the spindle increased its rotational speed automatically to keep surface speed constant. Finally, the spindle was stopped (point D).

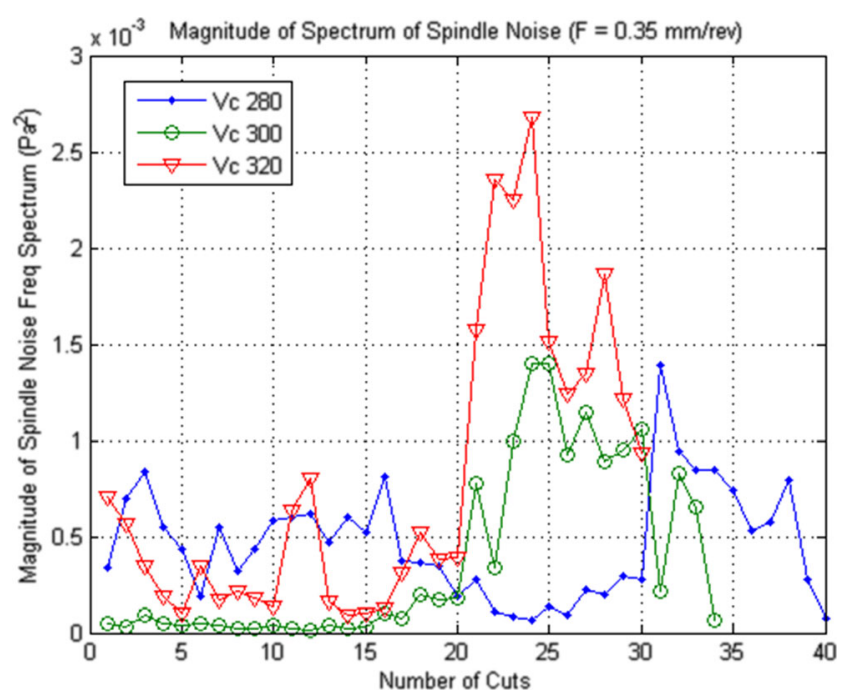

Fig. 8 Spindle noise for each individual cut at different cutting conditions 


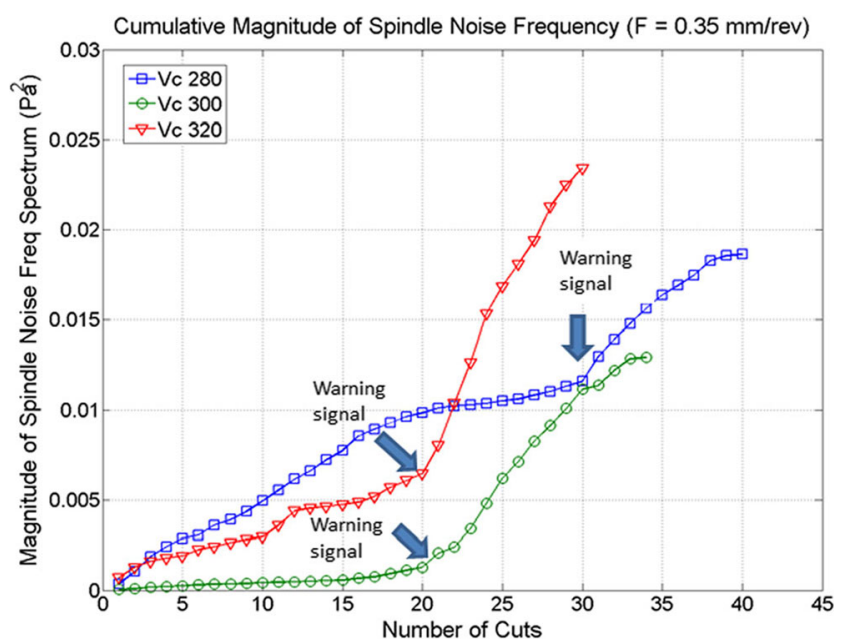

Fig. 9 Cumulative magnitude of spindle noise for each cut at different cutting conditions

The frequency band representing the coolant entering the cutting zone can be seen from point $\mathrm{F}$ to $\mathrm{G}$.

Over the range of spindle noise frequency, it can be observed that during cutting both intensity and frequency of cutting sound change from high to low represented by the broad sweep of higher intensity from top left to bottom right of Fig. 4. Many of the previous studies in this area use the sound signals present in the frequency range above machine background noise to develop the tool wear monitoring system [6-15]. However, as there is little reporting of using spindle noise in tool wear monitoring, this present work concentrates on the spindle noise signal as a signal of interest to extract a promising feature for tool condition monitoring. The changes in frequency and magnitude of spindle noise were observed by FFT. This observation was repeated for all of the machining trials performed and it was observed that the spindle noise was detected at $5.86 \mathrm{kHz}$ regardless of cutting conditions used on this particular machine.

This indicates that there is no significant correlation between the frequency of spindle noise and the development of tool wear. In order to study the influence of cutting parameters on the magnitude of spindle noise frequency, power spectrum of spindle noise frequency were plotted in combination of cutting speeds and feed rates which are now discussed.

\subsection{The effect of feed rate on the spindle noise and detecting tool wear}

For the trials where cutting speed was held constant and feed rate was varied (Fig. 6), it is seen that the onset of the rise in magnitudes of the power spectrum of spindle noise occurs earlier as the feed rate is increased. This means that the amount of warning (time) the system can give the operator is dependent on the feed rate being used, i.e. the greater the feed, the earlier the warning. a) $V_{c}=280, F=0.35$

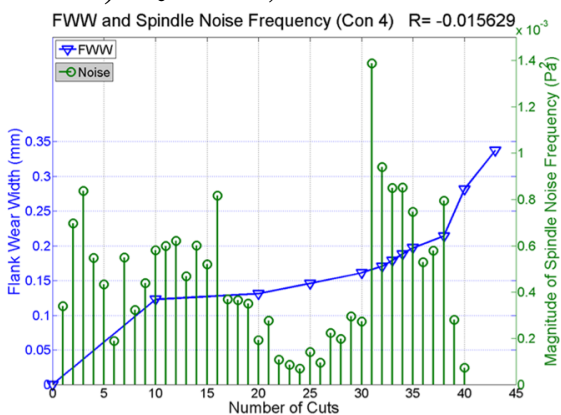

d) $V_{c}=280, F=0.4$

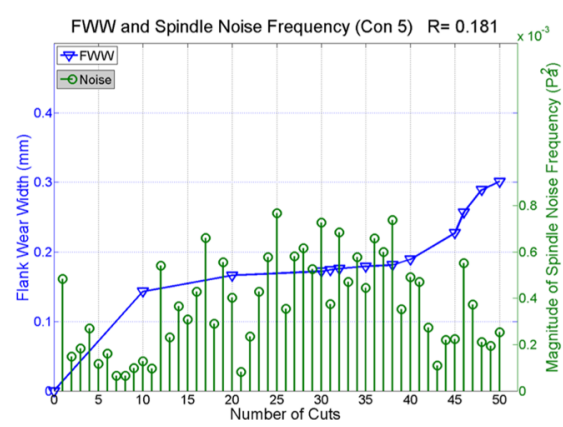

b) $\mathrm{V}_{\mathrm{c}}=300, \mathrm{~F}=0.35$

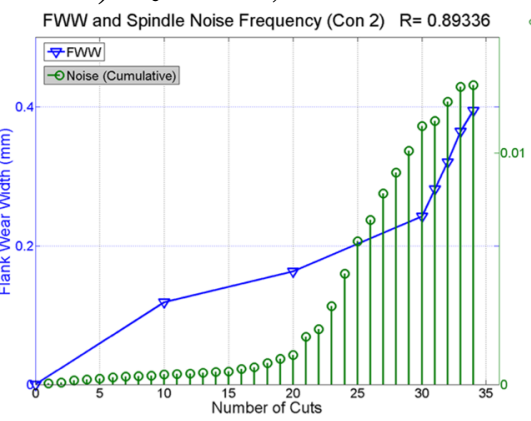

e) $V_{c}=300, F=0.4$

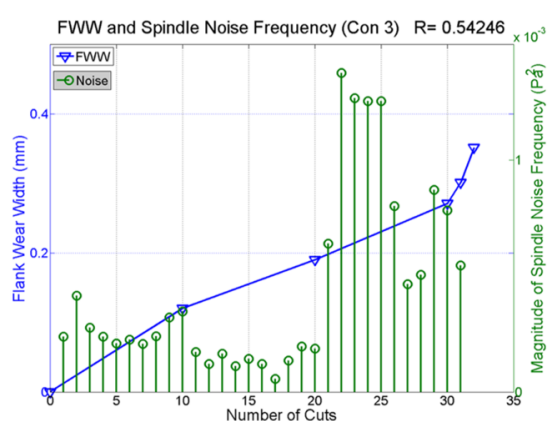

c) $\mathrm{V}_{\mathrm{c}}=320, \mathrm{~F}=0.35$

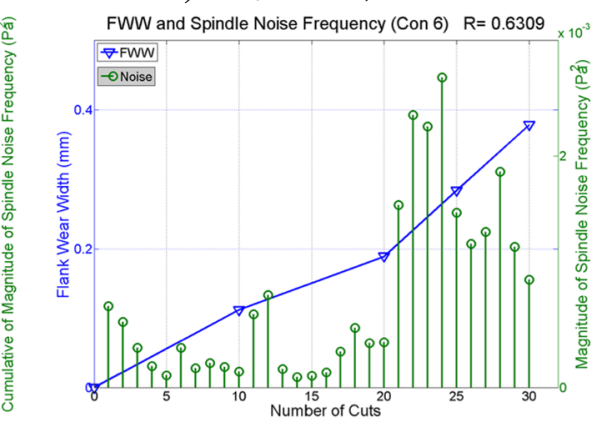

f) $V_{c}=320, F=0.4$

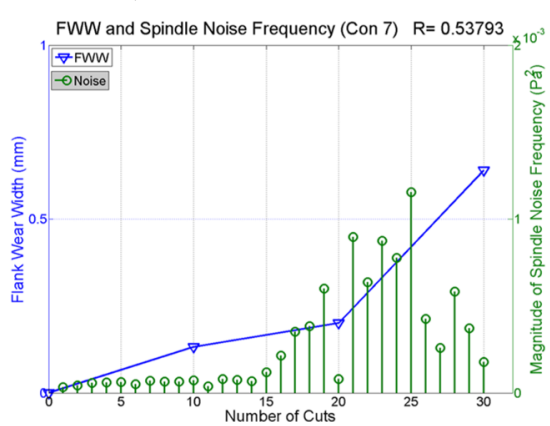

Fig. 10 Magnitude of power spectrum of spindle noise and flank wear width (FWW) vs. varying cutting speed and feed rate 
a) $\mathrm{V}_{\mathrm{c}}=280, \mathrm{~F}=0.35$

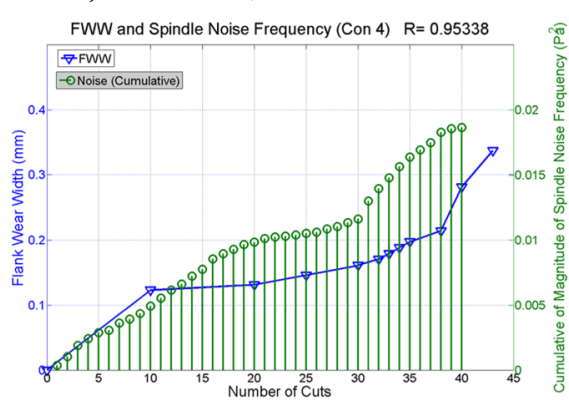

d) $V_{c}=280, F=0.4$

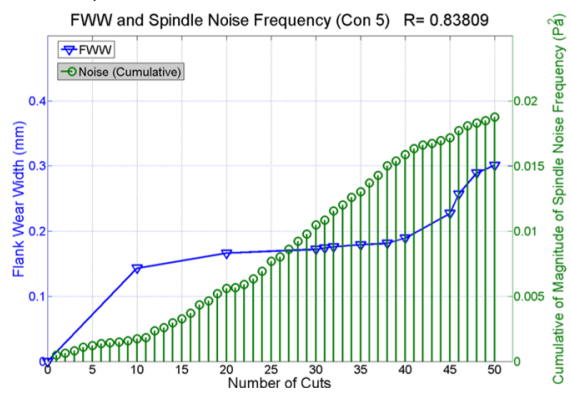

b) $\mathrm{V}_{\mathrm{c}}=300, \mathrm{~F}=0.35$

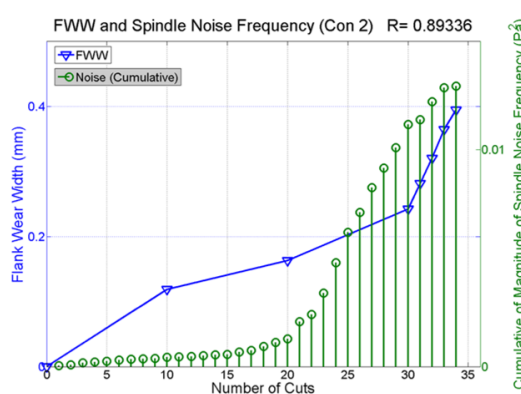

e) $V_{c}=300, F=0.4$

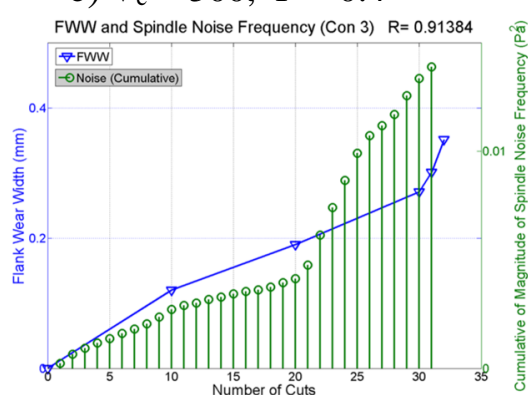

c) $\mathrm{V}_{\mathrm{c}}=320, \mathrm{~F}=0.35$

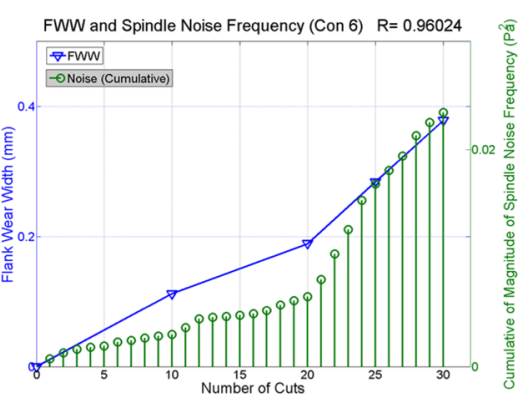

f) $\mathrm{V}_{\mathrm{c}}=320, \mathrm{~F}=0.4$

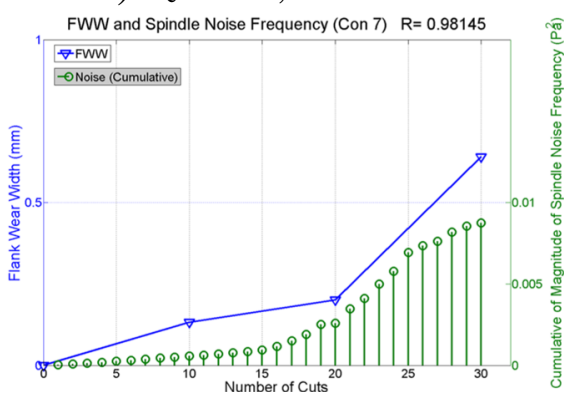

Fig. 11 Cumulative of the power spectrum magnitude of spindle noise and flank wear width (FWW)

The cumulative magnitude of spindle noise frequency was plotted in Fig. 7 that each of curve was clearly separated and has a warning signal at the turning point itself.

It is apparent that when the data set appears to grow exponentially, this is the point at which the tool should be replaced or warning occurs. In this case, for simplicity, a threshold value has been set as a tool change criteria. For example, using a threshold do 0.008 , the ending points of tool usage are about cut number $25,30,35$ in feed $0.3,0.35$ and 0.4 , respectively. It is seen that the magnitudes of spindle noise increase according to increasing of feed rate which suggests that the amount of warning (time) the system can give the operator is dependent on the feed rate being used, i.e. the greater the feed, the earlier the warning.

\subsection{The effect of cutting speed on the spindle noise and detecting tool wear}

In order to observe the effect of cutting speed on spindle noise, the magnitude of the spindle noise frequency performed at constant feed rate $0.35 \mathrm{~mm} / \mathrm{rev}$ as shown in Fig. 8 . It can be seen that the spindle noise frequency of a new tool has a low magnitude in the power spectrum (cuts 1-20) and high magnitude for the worn tool. The magnitude of spindle noise frequency gradually decreases until the cutting insert becomes dull and broken.

The average magnitude of spindle noise increases with cutting speed $\left(\mathrm{V}_{\mathrm{c}}\right)$. As is expected, the cuts performed at a higher cutting speed $\left(V_{c} 320\right)$ have shorter tool life (cut 30) compared to the lower cutting speed $\left(\mathrm{V}_{\mathrm{c}} 280\right)$ (cut 40$)$. Warning signals
Fig. 12 Power consumption of spindle motor (a) at constant cutting speed $300 \mathrm{~m} / \mathrm{min}(\mathbf{b})$ at constant feed rate $0.35 \mathrm{~mm} / \mathrm{rev}$

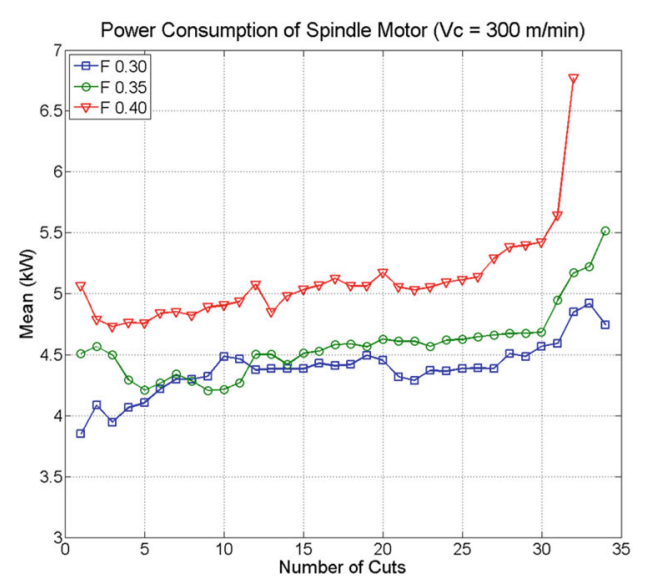

(a)

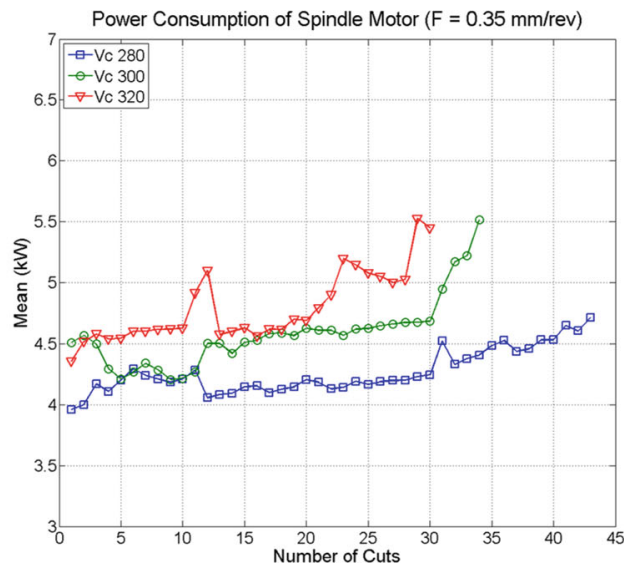

(b) 
can be indicated by the rate of increase of magnitude, observed in the plot as cut number 20 at cutting speed 300 , 320 and 30 at $280 \mathrm{~m} / \mathrm{min}$, as shown in Fig. 9.

It can be concluded that magnitude of spindle noise frequency has a good agreement with altered cutting conditions. When the cutting process performs at high metal removal rate (MMR), the spindle motor emits the noise with a higher magnitude of power spectrum of spindle noise frequency. The abrupt change in the power spectrum magnitude of spindle noise can be used as a warning signal for tool replacement.

It is worth noting that prior to the characteristic increase in magnitude indicating the onset on tool failure, the relative magnitudes of the signals from each of the different cutting speeds vary with the number of cuts (Fig. 8). Similarly, when considering the cumulative magnitude, although the warning signals are in the positions expected, the relative magnitude of the signals prior to those points are not as expected (Fig. 9). It is suggested that the cutting conditions used in these experiments are not different enough from each other to ensure any variation in the results due to non-uniformity of workpiece material and error in the experimental setup (e.g. changing workpiece position in the machine as it is consumed) do not overlap.

\subsection{Detecting tool wear}

Although the frequency of the spindle noise remains constant, this study found that the magnitude of spindle noise frequency alters in conjunction with the tool wear progression. The power spectrum of all cuts was individually calculated and illustrates that the magnitude of the power spectrum of the spindle noise frequency (multiple green lines) varies with tool wear (single blue line) as cutting takes place for the cutting conditions used in the machining trials (Fig. 10).

In general, and regardless of either considering the effect of varying cutting speed or feed, the magnitudes of the power spectrum of spindle noise are low when the tools are in their break-in period and until half way through their steady-state wear region. As cutting progresses, the power spectrum magnitudes of spindle noise increase rapidly until reaching their maximum value just prior to a sudden decrease just before tool failure.

The cumulative of spectrum magnitudes comparing to flank wear during cutting are shown in Fig. 11. It is observed that the trends of the cumulative data slightly increase from the start to half of the steady-wear period. Later, an abrupt change is observed in the second half of the steady-state wear period. This can be used as a warning signal to indicate imminent tool failure.

By considering the derivative of cumulative value, the condition of the tool can be monitored. It is normally low in the first and middle of the second periods of tool wear curve or tool flank wear less than $0.2 \mathrm{~mm}$. The significant change of derivative value is warned at the middle of steady wear. In failure region of tool wear curve, the derivative value intends to decrease to zero which is the point of tool failure.

It has been seen that an increase in the spectrum magnitude of spindle noise results from tool wear. As flank wear width increases, the contact area between flank face and workpiece increases which requires more cutting force and consequently, the spindle motor requires more power to rotate the workpiece at the desired speed to overcome the increasing friction force on the cutting contact area. The power consumption of spindle motor was monitored and Fig. 12 shows the power used of spindle motor during cutting, which increase significantly.

This increasing power for workpiece rotation produces more spindle noise. The increase in noise that this process produces is clearly recorded by the microphone and can be used as an indicator of the onset of unwanted levels of tool wear; therefore, using spindle noise can be a candidate feature for tool wear monitoring in a turning process.

It should also be noted that although a constant depth of cut was used in this work (as discussed in Section 2.1) it is expected that a similar relative change in the signal would be observed if it was also varied because the power consumption of a cutting process is related to the material removal rate (i.e. the product of depth of cut, cutting speed and feed). Similarly, it would be expected that repeating this work using different workpiece materials would produce measureable differences, for example using a workpiece of higher hardness (e.g. Inconel) would lead to higher tool wear (and therefore more noise) for a given cutting condition.

A limitation of this work, however, is that monitoring tool wear using spindle power consumption is not adequate for low cutting force turning operations, and also has fluctuated pattern resulted from the temperature effect of spindle motor.

\section{Conclusions}

The conclusions of this work were as follows:

1. It has been shown that the use of relative simple and inexpensive instrumentation can produce data that is of high enough quality to contribute to the condition monitoring of a running cutting process.

2. The sound analysis process described can be used to easily characterise a particular machining process by recording its audio signature and remove any unwanted environmental noise.

3. There is no significant correlation between the frequency of spindle noise and tool wear, but it is possible to infer basic knowledge about tool condition from the response of the magnitude of power spectrum of noise from the spindle to changing cutting speed and feed rate. 
4. The magnitude of spindle noise frequency spectrum and its cumulative value could be used as monitoring features in tool condition monitoring to assist with the selection of more expensive instrumentation hardware or in combination with similarly cost-effective sensors to provide a low cost tool wear monitoring system.

Acknowledgments This research has been supported by the University of Sheffield Advanced Manufacturing Research Centre with Boeing (AMRC) for experimental facilities. The authors also acknowledge the financial support provided by the Royal Thai Government.

Open Access This article is distributed under the terms of the Creative Commons Attribution 4.0 International License (http:// creativecommons.org/licenses/by/4.0/), which permits unrestricted use, distribution, and reproduction in any medium, provided you give appropriate credit to the original author(s) and the source, provide a link to the Creative Commons license, and indicate if changes were made.

\section{References}

1. Rehorn AG, Jiang J, Orban PE (2005) State-of-the-art methods and results in tool condition monitoring: a review. Int J Adv Manuf Technol 26(7-8):693-710. doi:10.1007/s00170-004-2038-2

2. Astakhov VP (2004) The assessment of cutting tool wear. Int J Mach Tools Manuf 44(6):637-647. doi:10.1016/j.ijmachtools.2003.11.006

3. Siddhpura A, Paurobally R (2013) A review of flank wear prediction methods for tool condition monitoring in a turning process. Int J Adv Manuf Technol 65(1-4):371-393. doi:10.1007/s00170-0124177-1

4. Teti R, Jemielniak K, O’Donnell G, Dornfeld D (2010) Advanced monitoring of machining operations. CIRP Ann Manuf Technol 59(2):717-739. doi:10.1016/j.cirp.2010.05.010

5. Stavropoulos P, Papacharalampopoulos A, Vasiliadis E, Chryssolouris G (2015) Tool wear predictability estimation in milling based on multi-sensorial data. Int J Adv Manuf Technol :1-13. doi:10.1007/s00170-015-7317-6

6. Worden K, Staszewski WJ, Hensman JJ (2011) Natural computing for mechanical systems research: a tutorial overview. Mech Syst Signal Process 25(1):4-111. doi:10.1016/j.ymssp.2010.07.013
7. Abellan-Nebot J, Romero Subirón F (2010) A review of machining monitoring systems based on artificial intelligence process models. Int J Adv Manuf Technol 47(1-4):237-257. doi:10.1007/s00170009-2191-8

8. Raja JE, Kiong LC, Soong LW (2013) Hilbert-Huang transformbased emitted sound signal analysis for tool flank wear monitoring. Arab J Sci Eng 38(8):2219-2226. doi:10.1007/s13369-013-0580-7

9. Kopac J, Sali S (2001) Tool wear monitoring during the turning process. J Mater Process Technol 113(1-3):312-316. doi:10.1016/ s0924-0136(01)00621-5

10. Mannan MA, Kassim AA, Jing M (2000) Application of image and sound analysis techniques to monitor the condition of cutting tools. Pattern Recogn Lett 21(11):969-979. doi:10.1016/S0167-8655(00) 00050-7

11. Tekıner Z, Yeșilyurt S (2004) Investigation of the cutting parameters depending on process sound during turning of AISI 304 austenitic stainless steel. Mater Des 25(6):507-513. doi:10.1016/j. matdes.2003.12.011

12. Quintana G, Ciurana J, Ferrer I, Rodriguez CA (2009) Sound mapping for identification of stability lobe diagrams in milling processes. Int J Mach Tools Manuf 49(3-4):203-211. doi:10.1016/j. ijmachtools.2008.11.008

13. Lu MC, Kannatey-Asibu E (2002) Analysis of sound signal generation due to flank wear in turning. J Manuf Sci Eng Trans ASME 124(4):799-808. doi:10.1115/1.1511177

14. Alonso FJ, Salgado DR (2005) Application of singular spectrum analysis to tool wear detection using sound signals. Proc Inst Mech Eng B J Eng Manuf 219(9):703-710. doi:10.1243/ 095440505x32634

15. Raja JE, Lim W, Venkataseshaiah C (2013) Tool condition monitoring using competitive neural network and Hilbert-Huang transform. Asian J Sci Res 6(4):703-714

16. Downey J, O’Leary P, Raghavendra R (2014) Comparison and analysis of audible sound energy emissions during single point machining of HSTS with PVD TiCN cutter insert across full tool life. Wear 313(1-2):53-62. doi:10.1016/j.wear.2014.02.004

17. Tangjitsitcharoen S, Rungruang C, Pongsathornwiwat N (2011) Advanced monitoring of tool wear and cutting states in CNC turning process by utilizing sensor fusion. In: Jiang ZY, Li SQ, Zeng JM, Liao XP, Yang DG (eds) Manufacturing Process Technology, Pts 1-5, vol 189-193. Advanced Materials Research. Trans Tech Publications Ltd, Stafa-Zurich, pp 377-384. doi:10.4028/www. scientific.net/AMR.189-193.377 